\title{
NY-ESO-1- and survivin-specific T-cell responses in the peripheral blood from patients with glioma
}

\author{
Zhenjiang Liu $^{1}$ - Thomas Poiret ${ }^{1,2}$ - Oscar Persson ${ }^{3} \cdot$ Qingda Meng $^{1} \cdot$ Lalit Rane $^{1} \cdot$ Jiri Bartek Jr. $^{3,4,5}$. \\ Julia Karbach $^{6}$ - Hans-Michael Altmannsberger ${ }^{7}$ - Christopher Illies $^{3} \cdot$ Xiaohua Luo $^{1}$ - Inti Harvey-Peredo ${ }^{3}$. \\ Elke Jäger $^{6} \cdot$ Ernest Dodoo $^{3} \cdot$ Markus Maeurer ${ }^{1,2}$
}

Received: 25 June 2016 / Accepted: 18 September 2017 / Published online: 20 October 2017

(c) The Author(s) 2017. This article is an open access publication

\begin{abstract}
The prognosis for patients with glioblastoma is grim. Ex vivo expanded tumor-associated antigen (TAA)reactive $\mathrm{T}$-cells from patients with glioma may represent a viable source for anticancer-directed cellular therapies. Immunohistochemistry was used to test the survivin $(n=40$ samples) and NY-ESO-1 ( $n=38$ samples) protein expression in tumor specimens. T-cells from peripheral blood were stimulated with TAAs (synthetic peptides) in IL-2 and IL-7, or using a combination of IL-2, IL-15 and IL-21. $\mathrm{CD}^{+}{ }^{+}$and $\mathrm{CD} 8^{+} \mathrm{T}$-cells were tested for antigen-specific
\end{abstract}

Elke Jäger, Ernest Dodoo, and Markus Maeurer are cosenior authors.

Electronic supplementary material The online version of this article (doi:10.1007/s00262-017-2066-z) contains supplementary material, which is available to authorized users.

Markus Maeurer

markus.maeurer@gmail.com

1 Therapeutic Immunology, F79, Department of Laboratory

Medicine, Karolinska University Hospital Huddinge,

Karolinska Institutet, Hälsovägen, Huddinge,

14186 Stockholm, Sweden

2 Centre for Allogeneic Stem Cell Transplantation (CAST), Karolinska University Hospital, Stockholm, Sweden

3 Department of Neurosurgery, Karolinska University Hospital, Stockholm, Sweden

4 Department of Clinical Neuroscience, Section for Neurosurgery, Karolinska Institutet, Stockholm, Sweden

5 Department of Neurosurgery, Copenhagen University Hospital Rigshopitalet, Copenhagen, Denmark

6 Department of Oncology and Hematology, Krankenhaus Nordwest, Frankfurt/Main, Germany

7 Institute of Pathology, Krankenhaus Nordwest, Frankfurt/Main, Germany proliferation by flow cytometry, and IFN- $\gamma$ production was tested by ELISA. Twenty-eight out of 38 cancer specimens exhibited NY-ESO-1 protein expression, 2/38 showed a strong universal (4+) NY-ESO-1 staining, and 9/40 cancer lesions exhibited a strong (4+) staining for survivin. We could detect antigen-specific IFN- $\gamma$ responses in $25 \%$ blood samples for NY-ESO-1 and 30\% for survivin. NY-ESO-1-expanded $\mathrm{T}$-cells recognized naturally processed and presented epitopes. NY-ESO-1 or survivin expression in glioma represents viable targets for anticancer-directed T-cells for the biological therapy of patients with glioma.

Keywords Glioma $\cdot$ Survivin $\cdot$ NY-ESO- 1 Cellular therapy $\cdot$ T-cells $\cdot$ Immunotherapy

$\begin{array}{ll}\text { Abbreviations } \\ \text { A } & \text { Astrocytoma } \\ \text { EBNA-3a } & \text { Epstein-Barr virus nuclear antigen } 3 \\ \text { FASCIA } & \text { Flow cytometric assay of specific cell-medi- } \\ & \begin{array}{l}\text { ated immune response in activated whole } \\ \text { blood }\end{array} \\ & \text { Glioblastoma multiforme } \\ \text { GBM } & \text { Intracellular cytokine staining } \\ \text { ICS } & \text { Interferon gamma } \\ \text { IFN- } \gamma & \text { Interleukin-2 } \\ \text { IL-2 } & \text { Oligoastrocytoma/oligodendroglioma } \\ \text { OA/O } & \text { Peripheral blood mononuclear cells } \\ \text { PBMCs } & \text { Phytohemagglutinin } \\ \text { PHA } & \text { Proliferation ratio } \\ \text { PR } & \text { Tumor-associated antigen } \\ \text { TAA } & \text { T-cell receptor } \\ \text { TCR } & \text { Tumor necrosis factor alpha } \\ \text { TNF- } \alpha & \text { Room temperature } \\ \text { RT } & \end{array}$




\section{Introduction}

Glioblastoma multiforme (GBM) has a grim prognosis [1]. The current standard treatment modalities are limited to surgery, radiation and temozolomide [2]. New treatment modalities are needed for patients with GBM, including adjunct cellular therapies targeting tumor-associated antigens (TAAs) in order to achieve better clinical outcomes [3]. Several TAAs have already been described, such as the spliced form of the EGFR, i.e., EGFRvIII [4, 5]. This mutation induces increased migration of tumor cells and is associated with radiation and chemotherapy resistance [6]. EGFRvIII has been demonstrated to be a tumor-specific antigen (TSA) for T-cell and B-cell responses [7] in biological therapy for patients with GBM. Other TAAs include the IL-13R $\alpha 2$, that is preferentially expressed in glioma, yet not in non-transformed cells [8]. IL-13R $\alpha 2$ may be targeted by $\mathrm{CD} 8^{+} \mathrm{T}$-cell responses or by chimeric antigen receptorengineered T-cells (CARs) [9, 10]. The IL-4R has also been found to be overexpressed in glioma cells, and IL-4 fused to a Pseudomonas toxin [IL-4 (38-37)-PE38KDL] has been shown to induce apoptosis of IL-4R-positive glioma cells [11]. A different tumor-associated antigen (TAA) is survivin, a member of the 'family of inhibitors of apoptosis' which is involved in cell cycle progression and apoptosis control [12]. Survivin is overexpressed in a number of human cancers [13], associated with poor prognosis [14], and able to stimulate survivin-reactive $\mathrm{CD} 8^{+}$T-cells $[15,16]$. NY-ESO-1, a member of the cancer-testis antigens, is expressed in about $20-40 \%$ of cancers $[9,17]$ and represents a promising target for anticancer-directed immune responses [17]. NY-ESO-1 was originally identified by serum screening (SEREX) and has been shown to induce potent MHC class I- and class IIrestricted T-cell responses [18]. Several other shared TAAs have been identified in GBM, including members of the MAGE family, neu/c-erbB-2, gp100 or MART-1/Melan-A [19]. NY-ESO-1 expression was reported to be low in glioma (1/30 glioma testing positive for NY-ESO-1), yet demethylating agents have been shown to increase TAA expression [20] leading to improved presentation of TAAs to T-lymphocytes. We tested survivin and NY-ESO-1 expression in brain cancer sections and examined TAA-reactive cellular immune responses in the corresponding blood samples from patients with glioma.

\section{Materials and methods}

\section{Diagnosis and patients}

Forty-six patients (Table 1) were enrolled in the study; the study was approved by the Regional Ethical Review Board at Karolinska Institutet, Stockholm, Sweden (Dnr:
Table 1 Summary of patient characteristics

\begin{tabular}{ll}
\hline Patient characteristics & $N=46$ \\
\hline Age median (years) & 58 years \\
Age range (years) & $30-76$ years \\
Sex (male/female) & $31 / 15$ \\
Diagnosis & \\
Glioblastomas & \\
$\quad$ Grade IV & 30 \\
Astrocytomas & \\
$\quad$ Grade II & 6 \\
$\quad$ Grade III & 3 \\
Oligodendrogliomas & \\
$\quad$ Grade II & 1 \\
Grade III & 2 \\
Mixed (0A) & \\
$\quad$ Grade II & 2 \\
Grade III & 2 \\
Relapse tumors & 3 \\
Secondary tumors & 3 \\
Corticosteroids & Betamethasone \\
Median (days) & 15 days \\
Range (months) & $0-9$ min \\
< 2 weeks & $27 / 46$ \\
2 weeks & $19 / 46$ \\
\hline
\end{tabular}

2013/576-31). Patients were divided into groups (Table 1) based on the WHO histopathological glioma grade (II, III, IV), as well as according to histology, i.e., oligoastrocytoma/ oligodendroglioma (OA/O), astrocytoma (A) and glioblastoma multiforme (GBM).

\section{Immunohistology}

\section{NY-ESO-1 staining}

Tumor tissue sections were cut, deparaffinized and treated with $3 \% \mathrm{H}_{2} \mathrm{O}_{2}$ in order to block endogenous peroxidase activity and to 'demask' for antigen retrieval. Forty tumor samples were available for survivin staining with sufficient amount of tumor material present for immunohistopathology. Either to the scarcity of resected tumor material available, or due to non-sufficient representative tumor material in individual sections, only 38/40 samples could be analyzed for NY-ESO-1 protein expression. The primary monoclonal mouse anti-NY-ESO-1 (clone E978) provided by the Monoclonal Antibody Core Facility (MACF) at Sloan Kettering Institute for Cancer Research [21], diluted in antibody diluent, was added for $30 \mathrm{~min}$. Sections were then incubated with horseradish peroxides-conjugated ENVision for $30 \mathrm{~min}$. The final reaction was visualized by incubation with diaminobenzidine + substrate-chromogen, followed by 
counterstaining of sections with hematoxylin. Each tissue section was semiquantitatively scored based on the intensity of immunostaining as negative ( 0 tumor cells stain positive), focal (less than $5 \%$ of tumor cells stain positive) or positive (score $1=6-25 \%$, score $2=26-50 \%$, score $3=51-75 \%$, score $4=76-100 \%$ ) of the tumor area. Tissues from testis served as positive control. For negative controls, testis tissue and glioblastoma sections were stained only with the secondary antibody (Supplementary Fig. 1a) [22].

\section{Survivin staining}

Immunostaining for survivin was performed on 4- $\mu \mathrm{m}$ sections of formalin-fixed paraffin-embedded tissue using the Leica Bond-Max automated immunostaining system (Leica Biosystems AB, Kista, Sweden). For antigen retrieval, samples were incubated for $20 \mathrm{~min}$ at $100{ }^{\circ} \mathrm{C}$ with Bond Epitope Retrieval Solution 1 (Leica Biosystems). Slides were stained for $30 \mathrm{~min}$ at room temperature with the survivin polyclonal antibody RB-9245 (Thermo Scientific), diluted 1:200. The percentage of positive cells was evaluated using a semiquantitative score: $1+<10 \%, 2+=10-20 \%, 3+=20-50 \%$ and $4+>50 \%$ of the tumor area (Supplementary Fig. 1b).

\section{Whole-blood assay (WBA) and IFN- $\gamma$ ELISA}

Whole blood was obtained at the time of diagnosis from patients with gliomas (i.e., prior to surgery, radiation and chemotherapy), diluted 1:1.5 with RPMI 1640 L-glutamine $(2 \mathrm{mM})$ with antibiotics (penicillin, $100 \mathrm{IU} / \mathrm{mL}$, and streptomycin, $100 \mu \mathrm{g} / \mathrm{mL}$ ) (Life Technologies, Carlsbad, USA) and incubated (i) without cytokines (RPMI only), (ii) with a IL-7 (10 ng/ml)/IL-2 (500 IU/ml) cytokine cocktail or (iii) with a IL-2 (1000 IU/ml)/IL-15 (10 ng/ml)/IL-21 (10 ng/ml) cytokine cocktail (Prospec, Ness Ziona, Israel). The diluted blood was co-incubated in pre-coated plates with a panel of different TAA and viral antigens (Supplementary Table 1) for 7 days at $37{ }^{\circ} \mathrm{C}$ and $5 \% \mathrm{CO}_{2}$ as described previously [23, 24]. To gauge the basal IFN- $\gamma$ production to NY-ESO-1, survivin as well as commonly recognized target antigens, blood was incubated with medium (negative control) and non-tumor-related antigens, i.e., the Epstein-Barr virus nuclear antigen 3 (EBNA-3). Positive controls were phytohemagglutinin (PHA, Sigma-Aldrich), OKT3 (anti-CD3 monoAb, Biolegend, CA, USA, $30 \mathrm{ng} / \mathrm{ml}$ ) and SEA + SEB (staphylococcal enterotoxin $\mathrm{A}$ and $\mathrm{B}$ ). IFN- $\gamma$ production was then quantified in the cell culture supernatant by ELISA (Mabtech, Stockholm, Sweden).

\section{FASCIA $C D 3^{+} / C D 4^{+} / C D 8^{+}$proliferation}

On day 7, cell culture supernatants were harvested, and blood of the duplicate wells was collected and washed with phosphate-buffered saline (PBS). Cells were then stained with the flow-cytometric assay of specific cell-mediated immune response in activated whole blood (FASCIA) test [25] with a cocktail of monoclonal surface antibodies anti-CD3 FITC, anti-CD4 APC and anti-CD8 PerCP. After incubation of $15 \mathrm{~min}$ at $+4{ }^{\circ} \mathrm{C}$, red blood cells were lysed using a Pharm lysing buffer (BD Biosciences, CA, USA) for $10 \mathrm{~min}$, and cells were then incubated for $5 \mathrm{~min}$ at room temperature. The immune cells were then resuspended in PBS and analyzed using a FACSCalibur flow cytometer (BD Biosciences, CA, USA) and FlowJo analytical software (Treestar, OR, USA). The proliferation ratio was calculated with resting and activated cells (blasts) according to their size and granularity: $\mathrm{PR}=$ blast/(resting cells + blast). The stimulation percentage (SP\%) was defined as the negative (medium) and positive (PHA) control proliferation ratio: $\mathrm{SP} \%=\left(\mathrm{PR}_{\mathrm{Ag}}-\mathrm{PR}_{\text {medium }}\right) /\left(\mathrm{PR}_{\mathrm{PHA}}-\mathrm{PR}_{\text {medium }}\right) \times 100$ as described in detail previously [25].

\section{Qualitative NY-ESO-1 and survivin IgG ELISA}

Plasma was obtained from patients with glioblastoma at the time of diagnosis, prior to surgery (and to radiation/chemotherapy), and stored at $-20{ }^{\circ} \mathrm{C}$. Plasma levels of antibodies against NY-ESO-1 or survivin were determined using an indirect IgG ELISA. Ninety-six-well plates (NUNC, Roskilde, Denmark) were coated with human $\mathrm{IgG}$ as a reference standard (ranging between 1875 and $15 \mathrm{ng} / \mathrm{ml}$ for NY-ESO-1 assay and between 500 and 3,9 $\mathrm{ng} / \mathrm{ml}$ for the survivin assay, Sigma-Aldrich, St. Louis, MI, USA) in a seven-point serial dilution (1:2 ratio); other wells contained the respective protein antigens (NY-ESO-1 and survivin, MyBioSource, San Diego, USA). The plate was incubated for $1 \mathrm{~h}$ at $37{ }^{\circ} \mathrm{C}$, washed three times with washing buffer (PBS 0.05\% Tween 20, Sigma-Aldrich, St. Louis, MI, USA) and then blocked with PBS 2\% BSA 0.05\% Tween 20 buffer, followed by incubation at room temperature for $1 \mathrm{~h}$ and five subsequent washing steps. Diluted patient samples were then incubated in duplicates for $2 \mathrm{~h}$ at room temperature (RT) and washed five times afterward. The plate was incubated with a secondary antihuman IgG, mAb (ALP conjugated, 1:1000 dilution, Mabtech, Stockholm, Sweden) for $1 \mathrm{~h}$ at RT and washed five times. Para-nitrophenyl phosphate (pNPP, Thermo Fisher Scientific, MA, USA) was added to the plate for $45 \mathrm{~min}$ at RT in the dark, and the reaction was stopped by adding $1 \mathrm{~N} \mathrm{NaOH}$. The optical density was measured at $405 \mathrm{~nm}$ and the anti-specific reactivity expressed as $\operatorname{IgG}$ equivalents.

\section{PBMCs isolation and culture}

PBMCs (peripheral blood mononuclear cells) were isolated from heparinized blood over a Ficoll-Hypaque gradient as 
described previously [26] prior to surgery, radiation and chemotherapy and preserved at $-190{ }^{\circ} \mathrm{C}$ using $90 \%$ fetal bovine serum (FBS, Life Technologies, Carlsbad, USA) and $10 \%$ DMSO. For T-cell expansion, PBMCs were cultured freshly after separation in CellGro (serum-free medium CellGenix, Freiburg, Germany) with 5\% pooled human AB serum (Innovative Research, Michigan, USA), supplemented with recombinant IL-2 (1000 IU/ml)/IL-15 (10 ng/ml)/IL-21 $(10 \mathrm{ng} / \mathrm{ml})$ (Prospec, Ness Ziona, Israel) in six-well plates (BD Falcon) at 2 million cells $/ \mathrm{mL}$ for 7 days with the respective antigens (NY-ESO-1 peptide mix or the survivin peptide mix; Peptides\&Elephants, Potsdam, Germany; the peptide concentration was $1 \mu \mathrm{g} / \mathrm{ml}$ for each peptide). At day 7 , cells were restimulated with irradiated autologous PBMCs at ratio 1:10, loaded with NY-ESO-1 or survivin peptides mix (at $1 \mu \mathrm{g} /$ peptide $/ \mathrm{ml}$ ) in the presence of cytokines as listed above. At day 10, OKT3 (anti-CD3 monoAb, Biolegend, CA, USA) was added at $30 \mathrm{ng} / \mathrm{mL}$ to the cell culture in order to amplify the specific immune response. Cells were harvested at day 18 and analyzed. If necessary, the culture medium was changed by replacing half of the culture volume. The targets were: NY-ESO-1 (SWISS PROT P78358) represents a peptide mix of $42 \times 15$ mer peptides with an 11 aa overlap which covers the entire length of the NY-ESO-1 sequence (180 aa); the survivin (SWISS PROT O15392) peptide mix represents $33 \times 15$ mer peptides with an 11 aa overlap covering the entire length of the survivin sequence (142 aa). Expanded T-cells were tested after harvest at day 18. After a single wash in PBS, 1 million cells were stained with the following Ab cocktail: anti-CD3 Percp (BD Biosciences, CA, USA), anti-CD4 Krome Orange (Beckman Coulter, CA, USA), anti-CD8a APC-Cy7 (BD Biosciences, CA, USA), anti-CD8 $\beta$ FITC (Beckman Coulter, CA, USA), anti-CD45RA ECD (Beckman Coulter, CA, USA) and antiCCR7 Brilliant Violet 421 (Biolegend, CA, USA).

\section{Immunophenotype, T-cell activation panel and tetramer-guided T-cell analysis}

One million T-cells were stained with the following $\mathrm{Ab}$ cocktail: anti-CD3 Brilliant Violet 570 (Biolegend, CA, USA), anti-CD4 Brilliant Violet 510 (Biolegend, CA, USA), anti-CD8a APC-Cy7 (BD Biosciences, CA, USA), anti-4-1BB FITC (eBioscience, CA, USA), anti-CD127 APC-AF700 (Beckman Coulter, CA, USA), anti-CD45RA ECD (Beckman Coulter, CA, USA), anti-CCR7 Brilliant Violet 421 (Biolegend, CA, USA), anti-LAG-3 APC (R\&D Systems, Minneapolis, MN), anti-CD25 PE-Cy7 (BD Biosciences, CA, USA), anti-CTLA-4 PE-Cy5 (BD Biosciences, CA, USA), anti-TIM3 Percp-eFluor710 (eBioscience, CA, USA) and anti-PD-1 PE (BD Biosciences, CA, USA). After 15 min, T-cells were washed with PBS- $0.1 \%$ FBS and analyzed using a FACSAria flow cytometer (BD Biosciences,
Stockholm, Sweden); data analysis was performed using FlowJo software.

\section{NY-ESO-1 tetramer}

PBMCs from HLA-A*0201-positive patients with GBM were stained with the HLA-A*02:01-restricted NY-ESO-1 antigen SLLMWITQV-PE ( $10 \mu \mathrm{L}$, Immudex, Copenhagen, Denmark) for $30 \mathrm{~min}$ at $37^{\circ} \mathrm{C}$ prior to washing with PBS- $0.1 \%$ FBS, followed by staining with the cell surface antibody cocktail described above.

\section{Tumor cell line culture and decitabine treatment}

Two glioma cell lines (DBTRG05-MG and SNB19) and the melanoma M624 tumor cell line were maintained in RPMI 1640 L-glutamine $(2 \mathrm{mM})$ with antibiotics (penicillin, $100 \mathrm{IU} / \mathrm{mL}$, and streptomycin, $100 \mu \mathrm{g} / \mathrm{mL}$ ) and $10 \% \mathrm{FBS}$ (Life Technologies, Carlsbad, USA). The HLA-A2 ${ }^{+}$glioma tumor and melanoma cell lines were treated with decitabine (Selleckchem, Houston, USA) at $1 \mu \mathrm{M}$ as described previously [27].

\section{Real-time PCR analysis of NY-ESO-1 expression}

Total RNA was extracted from DBTRG05-MG and SNB19 and M624 using the AllPrep DNA/RNA Mini Kit (Qiagen Inc., Hilden, Germany) according to the supplier's instructions. cDNA synthesis and real-time PCR analysis of NYESO-1 expression in tumor cell lines were performed as described previously by Odunsi K et al. [28].

\section{NY-ESO-1-specific T-cell isolation and T-cell tumor co-culture}

Two different methods were used in order to isolate NYESO-1-specific T-cells from PBMCs of two HLA-A2+ patients with glioma after expansion as described earlier. (i) After expansion, cells were stained with the NY-ESO-1 HLA-A2 dextramer reagent (Immudex, Denmark) for 30 min at RT and then stained with cell surface markers: ECD anti-CD3 Ab (Beckman Coulter, CA, USA), V450 anti-CD4 Ab (BD Biosciences, CA, USA) and the Percp anti-CD8 Ab (BD Biosciences, CA, USA) for $15 \mathrm{~min}$ at $4{ }^{\circ} \mathrm{C}$. (ii) NY-ESO-1 HLA-A2 dextramer-specific cells were sorted using an Aria flow cytometer (BD Biosciences, Stockholm, Sweden). After NY-ESO-1 peptide-driven expansion, T-cells were stimulated with the NY-ESO-1 peptide mix (Peptides\&Elephants, Custom Product) for $6 \mathrm{~h}$ at $37{ }^{\circ} \mathrm{C}, 5 \% \mathrm{CO}_{2}$, and NY-ESO-1-specific T-cells were purified with the IFN- $\gamma$ Production Assay Cell Enrichment and Detection Kit (PE) (Miltenyi Biotec, CA, USA) according to the supplier's instructions. After 
separation, NY-ESO-1-specific T-cells were exposed to tumor cells $( \pm$ decitabine pretreatment) in duplicates in 96-well plates and T-cell responses were blocked with W6/32 (anti-HLA-A, B, C; Sigma-Aldrich, St. Louis, USA) or L243 (anti-HLA-DR; Biolegend, San Diego, CA, USA) at $1 \mu \mathrm{g} /$ well. T-cells were cultured at a E/T ratio of 4:1 for T-cells from dextramer-sorted T-cells and at 5:1 for T-cells isolated by IFN- $\gamma$ capture. Supernatants were harvested at day 3 and tested for IFN- $\gamma$ by ELISA (Mabtech, Stockholm, Sweden).

\section{Statistical analysis}

Differences between patient groups (i.e., $\mathrm{G}$ versus A versus OA/O or 4 versus 3 versus 2) or within each group (i.e., comparing medium culture versus cultures with antigens) were analyzed using the Mann-Whitney $U$ test or the Wilcoxon test using GraphPad Prism 6 software. The Spearman test and linear regression analysis with the GraphPad software were used to test the correlations.

\section{Results}

\section{Survivin and NY-ESO-1 protein expression in gliomas}

Tumor sections were tested for NY-ESO-1 and survivin protein expression (Fig. 1 and Supplementary Fig. 1a, b). In 40 sample sections, analyzed for survivin, $22.5 \%$ (9/40) scored 4+, 27.5\% (11/40) scored 3+, 25\% (10/40) scored $2+$ and 25\% (10/40) scored 1+ (Supplementary Table 2). Most of the 'high score' sections testing positive for survivin represent grade IV glioma (18/20). Twenty-eight out of 38 GBM specimens tested positive for NY-ESO-1: 5.26\% $(2 / 38)$ scored as $4+, 2.63 \%(1 / 38)$ exhibited a score of $3+$, $7.89 \%(3 / 38)$ tested for $2+, 23.68 \%$ (9/38) of samples tested $1+, 34.21 \%(13 / 38)$ of samples exhibited focal staining and $26.31 \%$ (10/38) of samples tested negative (Table 2 and Supplementary Table 2).

\section{IFN- $\gamma$ production and cellular proliferation in response to TAAs}

NY-ESO-1 and survivin were tested to drive cellular proliferation and IFN- $\gamma$ production in blood from patients with
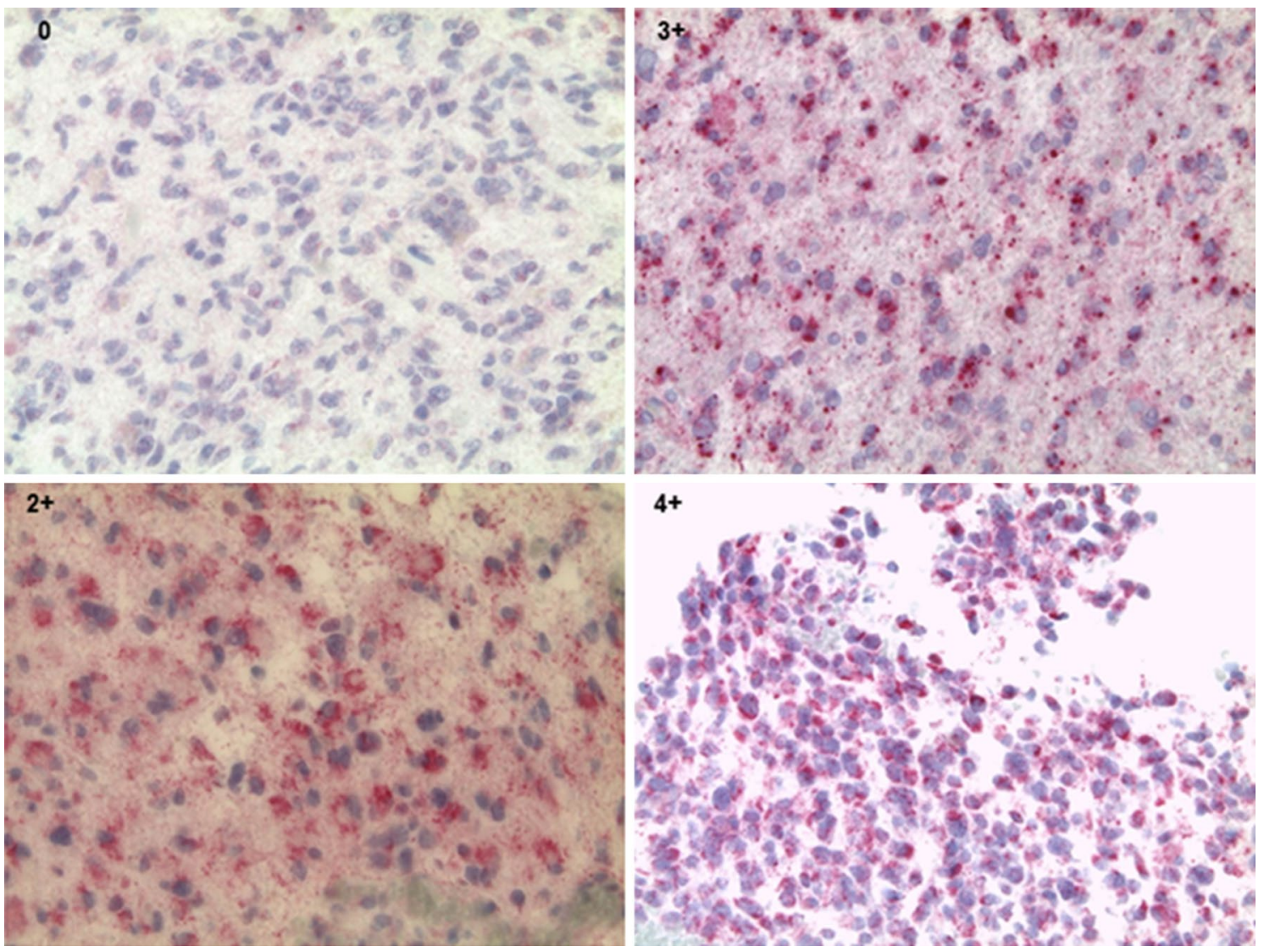

Fig. 1 Immunohistology of NY-ESO-1, magnification $\times 40$. Each tissue section was semiquantitatively scored based on the intensity of immunostaining: $0=$ tumor cells stain negative. Positive: score $2=26-50 \%$, score $3=51-75 \%$, score $4=76-100 \%$ of the tumor area 
Table 2 NY-ESO-1 and survivin protein expression

\begin{tabular}{|c|c|c|c|c|c|c|c|c|c|c|c|}
\hline \multirow[t]{2}{*}{ Diagnosis } & \multirow[t]{2}{*}{ Grade } & \multicolumn{4}{|c|}{ Survivin score $(n=40)$} & \multicolumn{6}{|c|}{ NY-ESO-1 score $(n=38)$} \\
\hline & & $1+$ & $2+$ & $3+$ & $4+$ & Neg & Focal & $1+$ & $2+$ & $3+$ & $4+$ \\
\hline \multirow[t]{3}{*}{ Astro/GBM } & 2 & 4 & 2 & & & 1 & 2 & 2 & & 1 & \\
\hline & 3 & 2 & & & & & & & 1 & & \\
\hline & 4 & 3 & 5 & 9 & 9 & 7 & 10 & 5 & 2 & & 1 \\
\hline \multirow[t]{2}{*}{ Oligo/mixed } & 2 & 1 & 1 & & & & & 2 & & & \\
\hline & 3 & & 2 & 2 & & 2 & 1 & & & & 1 \\
\hline Total & 10 & 10 & 11 & 9 & 10 & 13 & 9 & 3 & 1 & 2 & \\
\hline
\end{tabular}

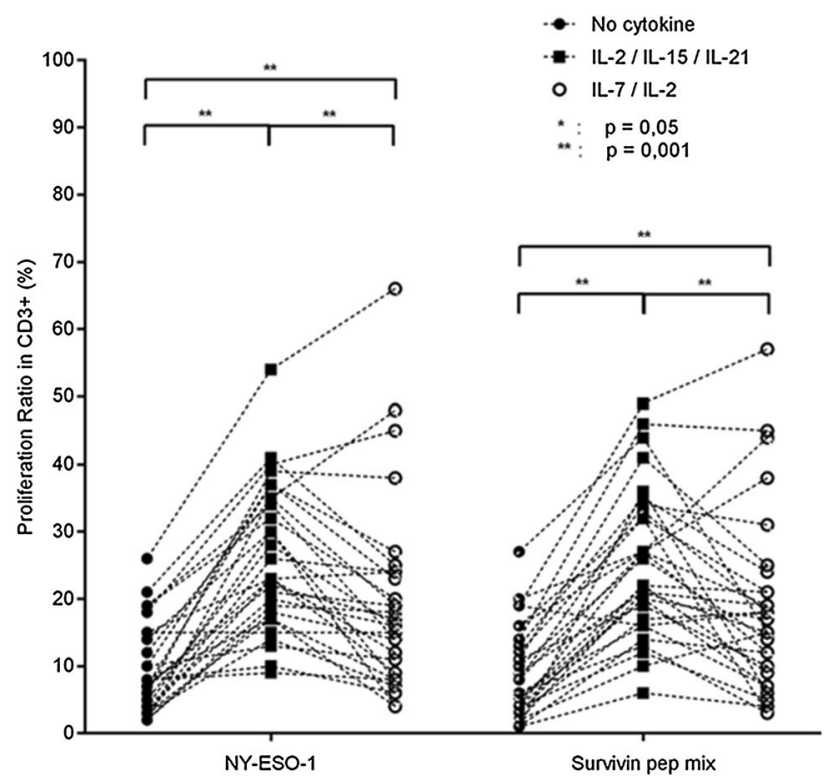

Fig. 2 T-cell proliferation ratio after a 7-day expansion of peripheral blood with NY-ESO-1 or the survivin peptide mix. Three different conditions: (i) without cytokines (RPMI only), (ii) with a IL-7/IL-2 cytokine cocktail or (iii) with a IL-2/IL-15/IL-21 cytokine cocktail $\left({ }^{*} p \leq 0.05,{ }^{* *} p \leq 0.001\right)$

GBM, as well as to control antigens, including frequently recognized Flu targets (H1N1, H1N5), as well as to negative controls, e.g., Mycobacterium tuberculosis targets (Supplementary Figs. 2a, b and 3). We identified an association of TAA-reactive T-cells (defined by IFN- $\gamma$ production) in correlation with the histopathological grading of the tumor and T-cells cultured with IL-2/IL-15 and IL-21. Stronger IFN- $\gamma$ production was identified in PBMCs from patients with histopathological grade III tumors as compared to patients with a grade IV tumor in response to NY-ESO-1 $(p=0.0135)$; this observation was also found to be true for IFN- $\gamma$ production to the survivin peptide mix ( $p=0.0062$, Supplementary Fig. 4). The cellular proliferation ratio was increased using IL-2/IL-15/IL-21 as compared to IL-2/IL-7-driven T-cell expansion for the antigen NY-ESO-1 $(p=0.0014)$ (Fig. 2). We did not observe differences concerning the proliferative index between the IL-2/IL-7 and IL-2/IL-15/IL-21 cytokine cocktails for survivin-driven T-cell expansion. Of note, the IL-2/IL-15/IL-21 cytokine combination particularly increased the $\mathrm{CD}^{+} \mathrm{T}$-cell population as compared to other culture conditions (IL-2/IL-7 or medium without cytokines) in response to the survivin peptide mix $(p=0.0013)$.

\section{IFN- $\gamma$ production in response to individual TAA peptides}

TAA-driven T-cell expansion was tested with peptides covering the entire NY-ESO-1 or the survivin protein. We tested additionally single peptides from survivin and from NY-ESO-1 (see "Materials and methods" section) that have previously been reported as 'hot spots' for immunodominant $\mathrm{T}$-cell recognition. The subsequent $\mathrm{T}$-cell response was measured by IFN- $\gamma$ production, and cellular proliferation was evaluated after a 7-day incubation. We did not identify significant differences among the three different culture conditions (no cytokines, IL-2/IL-7 or IL-2/IL-15/IL-21) concerning TAA-driven expansion of lymphocytes using a single survivin peptide, or individual peptides derived from NY-ESO-1, i.e., peptides NY-ESO-1 80-94 or 89-103 or 157-171 (Fig. 3). We observed stronger T-cell reactivity, using IL-2/IL-15/IL-21, defined by IFN- $\gamma$ production in blood from patients with grade III glioma as compared to blood from patients with grade II glioma ( $p=0.045)$ using a single peptide epitope from survivin that has previously been reported to be immunodominant and to be presented by a broad range of MHC alleles [29] (Supplementary Fig. 4).

\section{Humoral immune responses against TAAs}

Specific IgG against TAAs from patients with glioma was compared with IgG obtained from healthy donors (matched for age and gender). The humoral response against NY-ESO-1 was found to be significantly higher among patients with glioma as compared to anti-NYESO-1 IgG responses found in the age- and sex-matched (healthy) donors. The specific anti-survivin IgG among patients with glioma exhibited a stronger response as compared to the humoral response from healthy donors 
Fig. 3 IFN- $\gamma$ production after a 7-day expansion of peripheral blood with single TAA peptide antigens that have been shown to be immunodominant (survivin 97-111, the peptides NY-ESO-1 80-94, 89-103 and 157-171); three different conditions: (i) without cytokine (RPMI only), (ii) with a IL-7/ IL-2 cytokine cocktail or (iii) with a IL-2/IL-15/IL-21 cytokine cocktail. Data shown after subtraction of the constitutive IFN- $\gamma$ production

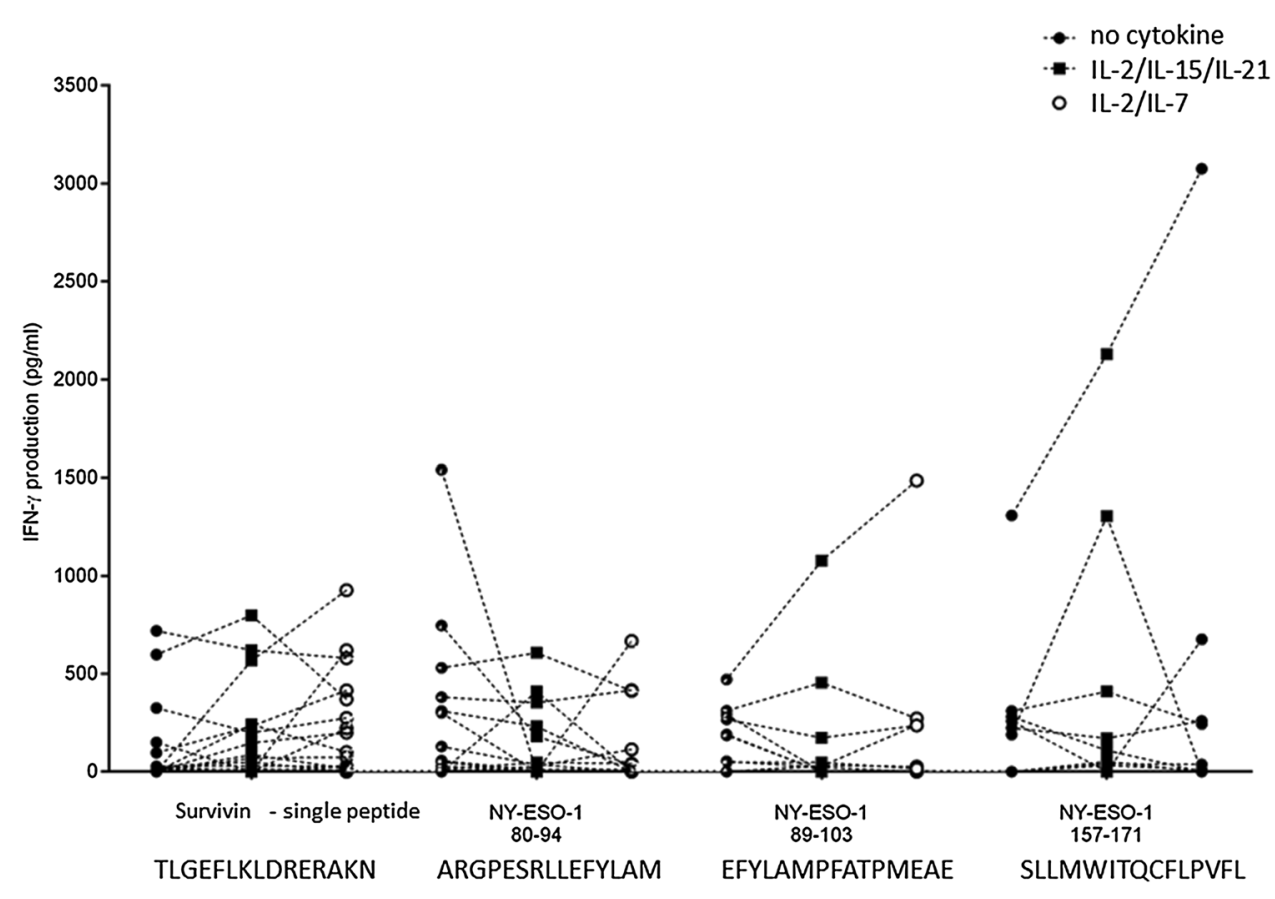

against survivin. A correlation analysis of immunohistology with humoral response is reported in detail in Supplementary Fig. 5.

\section{Expansion of antigen-specific T-cells from PBMCs}

In order to evaluate the cytokine production at a singlecell level, we expanded PBMCs (after Ficoll separation) from five patients with the NY-ESO- 1 or the survivin peptide mix in the presence of IL-2/IL-15/IL-21 and tested T-cell maturation (based on CD45RA/CCR7 marker expression, Supplementary Fig. 6) and T-cell activation, including 4-1BB. NY-ESO-1- or survivin-driven $\mathrm{T}$-cell expansion resulted in different frequencies of antigen-specific $\mathrm{CD}^{+}{ }^{+}$and $\mathrm{CD} 8^{+} \mathrm{T}$-cells (defined by $4-1 \mathrm{BB}$ reactivity) ranging from 2.78 to $26.5 \% \mathrm{CD}^{+} \mathrm{T}$-cells (Supplementary Table 3 and Supplementary Fig. 7). NYESO-1-specific T-cell responses, i.e., cytokine production defined by ICS, were detectable in T-cells from patients whose tumor lesions stained positive for NY-ESO-1 protein expression (Supplementary Table 4). Anti-NY-ESO-1 reactivity was confirmed by MHC class I (HLA-A2 ${ }^{+}$)peptide-tetramer-guided staining showing up to $9.25 \%$ HLA-A2 + (NY-ESO-1)-reactive T-cells (Supplementary Fig. 8). PBMCs $(50 \times 10 \mathrm{e} 6$ cells as the starting cell numbers) could consistently be expanded (PBMCs from $n=5$ individual patients with GBM) to more than $2 \times 10 \mathrm{e} 8$ T-cells (data not shown).

\section{NY-ESO-1 GBM tumor cells are recognized by sorted NY-ESO-1-specific T-cells}

In order to show that NY-ESO-1 (peptide)-expanded T-cells recognize naturally and presented tumor-associated peptides, we used decitabine that induces NY-ESO-1 expression in cell lines. GBM cell lines ( \pm decitabine), or a NYESO-1 + HLA-A2 ${ }^{+}$melanoma cell, were used as target cells and co-cultured with NY-ESO-1-specific T-cells isolated from two HLA-A2 ${ }^{+}$glioma patients (either by tetramerguided sorting, or by a cytokine capture assay, Supplementary Fig. 9). IFN- $\gamma$ production in NY-ESO-1+-sorted T-cells showed that NY-ESO-1-peptide-expanded T-cells were able to react against naturally processed and presented peptides on HLA-A2 ${ }^{+}$tumor cell lines.

\section{Discussion}

We tested NY-ESO-1 and survivin expression in gliomas and analyzed the corresponding patient's PBMCs for antiTAA reactivity. NY-ESO-1 expression in glioma was found to be low in a single study [30] as compared to the current report. A possible explanation for this difference may be the selection of patients. The patients in our cohort presented with a primary tumor prior to radiation or any chemotherapy [31]. NY-ESO-1 expression was also found to be patchy (this report); limited access to tumor material may therefore result in false negative results concerning protein expression. 
NY-ESO-1 and survivin expression was further consolidated by the presence of humoral anti-NY-ESO-1- and survivindirected $\mathrm{IgG}$ responses $[32,33]$ in the current patient cohort (see Supplementary Fig. 5). NY-ESO-1 protein expression in glioma may therefore open new therapeutic options, given the recent success of anti-NY-ESO-1-directed transgenic TCRs (for HLA-A2 ${ }^{+}$) individuals $[34,35]$, the use of antiNY-ESO-1-directed antibody therapies [36] or the use of anti-NY-ESO-1-directed vaccination strategies [37].

The proliferative capacity of PBMCs in response to TAAs suggests that NY-ESO-1- or survivin-directed T-cells can be expanded and used for the cellular therapy of patients with glioma: tetramer-guided or IFN- $\gamma$-captured NY-ESO-1-directed T-cells were shown to recognize naturally processed and presented epitopes, suggesting that peptide-driven expansion of T-cells leads to biologically and clinically relevant T-cell populations directed against tumor cells (see Supplementary Fig. 8).

The number of cellular therapies directed against tumorassociated antigens for patients with gliomas is limited up to now; a review of cell-based therapies suggests that infusion of immune cells may lead to improve survival along with limited therapy-associated toxicity. For instance, PBMCs were harvested for cellular therapy and CTL were generated directed against autologous (glioma) tumor cells (using a mix of PBMCs, autologous tumor cells and recombinant IL-2), followed by in situ administration $\left(10^{8}\right.$ up to $10^{9} \mathrm{~T}$-cells i.t.). Three out of five patients did not exhibit any benefit; $1 / 5$ patient showed a transient regression; and $1 / 5$ patient showed a complete regression that lasted 104 weeks [38]. TAAs could provide an 'off-the-shelf solution' to drive anticancer-directed T-cells. Alternate methods have been reported, i.e., (i) OKT3 stimulation of peripheral T-cells along with IL-2 was used to treat nine patients with glioma. Two out of nine patients (grade III glioma) experienced partial regression that lasted five years [39]. (ii) A different approach was the use of T-cells present in regional lymph nodes for adoptive therapy [40]. Two out of nine patients showed tumor regression, one of them a durable response that lasted 17 months. (iii) Treatment with LAK cells (lymphokine-activated killer cells) [41]: A single study was performed in patients with glioma after surgical resection, followed by intralesional application of LAK cells with a median survival of 53 weeks as compared to 25.5 weeks of the control group [42]. Dillmann and coworkers showed in phase II study a 25 -month median survival and a $75 \%$ 1-year survival in 40 patients with intralesional LAK cells; this study was performed in patients with newly diagnosed glioma [43]. Infusion of TIL $(n=6)$ obtained from patients with glioma suggested a clinically relevant benefit for individual patients with a complete response [44]. The data in our report show that NY-ESO-1 and survivin can now be added as a tumor-associated target for the biological treatment of patients with glioma, particularly since data from several NY-ESO-1-directed [45] or anti-survivindirected trials did not report [46] major toxicity.

The presence of not only anti-tumor-directed T-cells, but also their phenotypic profile and homing pattern appears to be responsible for clinical efficacy. Clinical experience from patients with melanoma showed that (tumor) antigenspecific T-cells persist, acquire a central memory phenotype and are able to mediate long-term (up to 3 years) remissions in some patients [47]. The CD45RA-CCR $7^{+}$central memory T-cell phenotype appears to be a key for long-lasting anti-tumor-directed cellular immune responses [48]. This T-cell phenotype may also be achieved expanding anti-NYESO-1- or survivin-directed T-cells, followed by infusion into patients with NY-ESO- $1^{+}$or survivin + gliomas. Of note, the $\mathrm{CD} 45 \mathrm{RA}-\mathrm{CCR} 7^{+}$central memory T-cell subset population, associated with increased responsiveness to therapy, was not depleted upon IL-2/IL-15/IL-21-driven expansion (see Supplementary Fig. 6).

A matter of discussion may be the absolute number of antigen-specific T-cells required for passive transfer of antigen-specific T-cells. Even low numbers of anti-TAA-directed T-cells may be able to mediate clinically relevant effects, since (i) conditioning of the patients, prior to T-cell infusion (using fludarabine and cyclophosphamide), will provide 'space' for T-cell expansion after adoptive transfer and upon encounter with the nominal target antigen expressed by the tumor, (ii) IL-21 in concert with IL-15 (cytokines used in the current report) prevents T-cell apoptosis of immune cells responding to antigenic stimulation [49] and (iii) data from experimental models suggest that low numbers of precursor T-cells are able to expand into effector T-cell populations [50]. We could also show that T-cells directed against NYESO-1 can be expanded from PBMCs obtained from healthy individuals (see Supplementary Table 5). The fact that low (absolute) numbers of TAA-reactive immune cells are able to mediate biologically relevant effects is supported by data after allogeneic stem cell transplantation, i.e., even low numbers of (tetramer-sorted) antigen (CMV)-specific T-cells, as low as 10.000 cells $/ \mathrm{kg}$ patient, are able to confer protective, clinically relevant target-specific cellular immune responses [51]. The fact that antigen-specific IFN- $\gamma$ responses could be detected in $25 \%$ blood samples for NY-ESO-1 and in $30 \%$ for survivin suggests that there is a viable TCR repertoire present capable of reacting to these nominal TAAs. Further studies are needed to examine whether (i) the extent of NY-ESO-1 or survivin protein expression is associated with increased numbers of antigen-specific T-cells and (ii) the TCR repertoire in 'non-responding' patients has been depleted due to prolonged antigen exposure.

Acknowledgements We thank our patients who participated in this study. 


\section{Compliance with ethical standards}

Conflict of interest The authors do not declare a conflict of interest.

Funding source The study was funded by Karolinska Institutet, the Söderberg Foundation and Vinnova.

Open Access This article is distributed under the terms of the Creative Commons Attribution 4.0 International License (http://creativecommons.org/licenses/by/4.0/), which permits unrestricted use, distribution, and reproduction in any medium, provided you give appropriate credit to the original author(s) and the source, provide a link to the Creative Commons license, and indicate if changes were made.

\section{References}

1. Goodenberger ML, Jenkins RB (2012) Genetics of adult glioma. Cancer Genet 205:613-621. doi:10.1016/j.cancergen.2012.10.009

2. Desjardins A, Reardon DA, Peters KB, Threatt S, Coan AD, Herndon JE 2nd, Friedman AH, Friedman HS, Vredenburgh JJ (2011) A phase I trial of the farnesyl transferase inhibitor, SCH 66336, with temozolomide for patients with malignant glioma. J Neurooncol 105:601-606. doi:10.1007/s11060-011-0627-0

3. Hegde M, Bielamowicz KJ, Ahmed N (2014) Novel approaches and mechanisms of immunotherapy for glioblastoma. Discov Med $17: 145-154$

4. Belli F, Testori A, Rivoltini L et al (2002) Vaccination of metastatic melanoma patients with autologous tumor-derived heat shock protein gp96-peptide complexes: clinical and immunologic findings. J Clin Oncol 20:4169-4180

5. Heimberger AB, Hlatky R, Suki D, Yang D, Weinberg J, Gilbert M, Sawaya R, Aldape K (2005) Prognostic effect of epidermal growth factor receptor and EGFRvIII in glioblastoma multiforme patients. Clin Cancer Res 11:1462-1466. doi:10.1158/1078-0432. CCR-04-1737

6. Batra SK, Castelino-Prabhu S, Wikstrand CJ, Zhu X, Humphrey PA, Friedman HS, Bigner DD (1995) Epidermal growth factor ligand-independent, unregulated, cell-transforming potential of a naturally occurring human mutant EGFRvIII gene. Cell Growth Differ 6:1251-1259

7. Sampson JH, Archer GE, Mitchell DA, Heimberger AB, Bigner DD (2008) Tumor-specific immunotherapy targeting the EGFRvIII mutation in patients with malignant glioma. Semin Immunol 20:267-275. doi:10.1016/j.smim.2008.04.001

8. Eguchi J, Hatano M, Nishimura F, Zhu X, Dusak JE, Sato H, Pollack IF, Storkus WJ, Okada H (2006) Identification of interleukin-13 receptor alpha2 peptide analogues capable of inducing improved antiglioma CTL responses. Cancer Res 66:5883-5891. doi:10.1158/0008-5472.CAN-06-0363

9. Okano F, Storkus WJ, Chambers WH, Pollack IF, Okada H (2002) Identification of a novel HLA-A*0201-restricted, cytotoxic T lymphocyte epitope in a human glioma-associated antigen, interleukin 13 receptor alpha 2 chain. Clin Cancer Res 8:2851-2855

10. Brown CE, Alizadeh D, Starr R et al (2016) Regression of glioblastoma after chimeric antigen receptor T-cell therapy. N Engl J Med 375:2561-2569. doi:10.1056/NEJMoa1610497

11. Joshi BH, Leland P, Silber J, Kreitman RJ, Pastan I, Berger M, Puri RK (2002) IL-4 receptors on human medulloblastoma tumours serve as a sensitive target for a circular permuted IL4-Pseudomonas exotoxin fusion protein. Br J Cancer 86:285-291. doi:10.1038/sj.bjc.6600034
12. Li F, Ambrosini G, Chu EY, Plescia J, Tognin S, Marchisio PC, Altieri DC (1998) Control of apoptosis and mitotic spindle checkpoint by survivin. Nature 396:580-584. doi:10.1038/25141

13. Schmidt SM, Schag K, Muller MR, Weck MM, Appel S, Kanz L, Grunebach F, Brossart P (2003) Survivin is a shared tumorassociated antigen expressed in a broad variety of malignancies and recognized by specific cytotoxic T cells. Blood 102:571576. doi:10.1182/blood-2002-08-2554

14. Islam A, Kageyama H, Takada N et al (2000) High expression of Survivin, mapped to $17 \mathrm{q} 25$, is significantly associated with poor prognostic factors and promotes cell survival in human neuroblastoma. Oncogene 19:617-623. doi:10.1038/sj.onc.1203358

15. Casati C, Dalerba P, Rivoltini L et al (2003) The apoptosis inhibitor protein survivin induces tumor-specific $\mathrm{CD} 8^{+}$ and $\mathrm{CD}^{+}{ }^{+} \mathrm{T}$ cells in colorectal cancer patients. Cancer Res 63:4507-4515

16. Idenoue $\mathrm{S}$, Hirohashi $\mathrm{Y}$, Torigoe $\mathrm{T}$ et al (2005) A potent immunogenic general cancer vaccine that targets survivin, an inhibitor of apoptosis proteins. Clin Cancer Res 11:1474-1482. doi:10.1158/1078-0432.CCR-03-0817

17. Jager E, Gnjatic S, Nagata Y et al (2000) Induction of primary NYESO-1 immunity: CD8 ${ }^{+} \mathrm{T}$ lymphocyte and antibody responses in peptide-vaccinated patients with NY-ESO- ${ }^{+}$cancers. Proc Natl Acad Sci USA 97:12198-12203. doi:10.1073/pnas.220413497

18. Jager D, Unkelbach M, Frei C, Bert F, Scanlan MJ, Jager E, Old LJ, Chen YT, Knuth A (2002) Identification of tumor-restricted antigens NY-BR-1, SCP-1, and a new cancer/testis-like antigen NW-BR-3 by serological screening of a testicular library with breast cancer serum. Cancer Immun 2:5

19. Scarcella DL, Chow CW, Gonzales MF, Economou C, Brasseur F, Ashley DM (1999) Expression of MAGE and GAGE in highgrade brain tumors: a potential target for specific immunotherapy and diagnostic markers. Clin Cancer Res 5:335-341

20. Natsume A, Wakabayashi T, Tsujimura $K$ et al (2008) The DNA demethylating agent 5-aza-2'-deoxycytidine activates NY-ESO-1 antigenicity in orthotopic human glioma. Int J Cancer 122:25422553. doi:10.1002/ijc. 23407

21. Jungbluth AA, Chen YT, Stockert E et al (2001) Immunohistochemical analysis of NY-ESO-1 antigen expression in normal and malignant human tissues. Int J Cancer 92:856-860. doi:10.1002/ ijc. 1282

22. Stockert E, Jager E, Chen YT, Scanlan MJ, Gout I, Karbach J, Arand M, Knuth A, Old LJ (1998) A survey of the humoral immune response of cancer patients to a panel of human tumor antigens. J Exp Med 187:1349-1354

23. Lagrelius M, Jones P, Franck K, Gaines H (2006) Cytokine detection by multiplex technology useful for assessing antigen specific cytokine profiles and kinetics in whole blood cultured up to seven days. Cytokine 33:156-165. doi:10.1016/j.cyto.2006.01.005

24. Alvarez-Corrales N, Ahmed RK, Rodriguez CA et al (2013) Differential cellular recognition pattern to M. tuberculosis targets defined by IFN-gamma and IL-17 production in blood from $\mathrm{TB}+$ patients from Honduras as compared to health care workers: $\mathrm{TB}$ and immune responses in patients from Honduras. BMC Infect Dis 13:125. doi:10.1186/1471-2334-13-125

25. Gaines H, Andersson L, Biberfeld G (1996) A new method for measuring lymphoproliferation at the single-cell level in whole blood cultures by flow cytometry. J Immunol Methods 195:63-72

26. Magalhaes I, Vudattu NK, Ahmed RK et al (2010) High content cellular immune profiling reveals differences between rhesus monkeys and men. Immunology 131:128-140. doi:10.1111/j.1365-2567.2010.03284.x

27. Konkankit VV, Kim W, Koya RC, Eskin A, Dam MA, Nelson S, Ribas A, Liau LM, Prins RM (2011) Decitabine immunosensitizes human gliomas to NY-ESO-1 specific T lymphocyte 
targeting through the Fas/Fas ligand pathway. J Transl Med 9:192. doi:10.1186/1479-5876-9-192

28. Odunsi K, Jungbluth AA, Stockert E et al (2003) NY-ESO-1 and LAGE-1 cancer-testis antigens are potential targets for immunotherapy in epithelial ovarian cancer. Cancer Res 63:6076-6083

29. Widenmeyer M, Griesemann H, Stevanovic S et al (2012) Promiscuous survivin peptide induces robust $\mathrm{CD} 4^{+} \mathrm{T}$-cell responses in the majority of vaccinated cancer patients. Int J Cancer 131:140 149. doi:10.1002/ijc. 26365

30. Sahin U, Koslowski M, Tureci O et al (2000) Expression of cancer testis genes in human brain tumors. Clin Cancer Res 6:3916-3922

31. Corso CD, Ali AN, Diaz R (2011) Radiation-induced tumor neoantigens: imaging and therapeutic implications. Am J Cancer Res $1: 390-412$

32. Fujiwara S, Wada H, Kawada J et al (2013) NY-ESO-1 antibody as a novel tumour marker of gastric cancer. Br J Cancer 108:11191125. doi:10.1038/bjc.2013.51

33. Uemura N, Kodama S, Nomi N, Okamoto T, Suzuki M (2010) Correlation between anti-survivin antibody and survivin mRNA expression in head and neck cancer patients. Acta Otolaryngol 130:959-965. doi:10.3109/00016480903555416

34. Robbins PF, Kassim SH, Tran TL et al (2015) A pilot trial using lymphocytes genetically engineered with an NY-ESO-1-reactive T-cell receptor: long-term follow-up and correlates with response. Clin Cancer Res 21:1019-1027. doi:10.1158/10780432.CCR-14-2708

35. Everson RG, Antonios JP, Lisiero DN et al (2016) Efficacy of systemic adoptive transfer immunotherapy targeting NY-ESO-1 for glioblastoma. Neuro Oncol 18:368-378. doi:10.1093/neuonc/ nov 153

36. Gupta A, Nuber N, Esslinger C et al (2013) A novel humanderived antibody against NY-ESO-1 improves the efficacy of chemotherapy. Cancer Immun 13:3

37. Dutoit V, Taub RN, Papadopoulos KP et al (2002) Multiepitope CD8(+) T cell response to a NY-ESO-1 peptide vaccine results in imprecise tumor targeting. J Clin Invest 110:1813-1822. doi:10.1172/JCI16428

38. Kitahara T, Watanabe O, Yamaura A, Makino H, Watanabe T, Suzuki G, Okumura K (1987) Establishment of interleukin 2 dependent cytotoxic $\mathrm{T}$ lymphocyte cell line specific for autologous brain tumor and its intracranial administration for therapy of the tumor. J Neurooncol 4:329-336

39. Tsurushima H, Liu SQ, Tuboi K, Matsumura A, Yoshii Y, Nose T, Saijo K, Ohno T (1999) Reduction of end-stage malignant glioma by injection with autologous cytotoxic T lymphocytes. Jpn J Cancer Res 90:536-545
40. Plautz GE, Miller DW, Barnett GH, Stevens GH, Maffett S, Kim J, Cohen PA, Shu S (2000) T cell adoptive immunotherapy of newly diagnosed gliomas. Clin Cancer Res 6:2209-2218

41. Rosenberg SA, Lotze MT, Muul LM et al (1985) Observations on the systemic administration of autologous lymphokine-activated killer cells and recombinant interleukin-2 to patients with metastatic cancer. N Engl J Med 313:1485-1492. doi:10.1056/ NEJM198512053132327

42. Hayes RL, Koslow M, Hiesiger EM et al (1995) Improved long term survival after intracavitary interleukin-2 and lymphokineactivated killer cells for adults with recurrent malignant glioma. Cancer 76:840-852

43. Dillman RO, Duma CM, Ellis RA, Cornforth AN, Schiltz PM, Sharp SL, DePriest MC (2009) Intralesional lymphokine-activated killer cells as adjuvant therapy for primary glioblastoma. J Immunother 32:914-919. doi:10.1097/CJI.0b013e3181b2910f

44. Quattrocchi KB, Miller CH, Cush S, Bernard SA, Dull ST, Smith M, Gudeman S, Varia MA (1999) Pilot study of local autologous tumor infiltrating lymphocytes for the treatment of recurrent malignant gliomas. J Neurooncol 45:141-157

45. Gnjatic S, Nishikawa H, Jungbluth AA, Gure AO, Ritter G, Jager E, Knuth A, Chen YT, Old LJ (2006) NY-ESO-1: review of an immunogenic tumor antigen. Adv Cancer Res 95:1-30. doi:10.1016/S0065-230X(06)95001-5

46. Kanwar RK, Cheung CH, Chang JY, Kanwar JR (2010) Recent advances in anti-survivin treatments for cancer. Curr Med Chem 17:1509-1515

47. Chapuis AG, Thompson JA, Margolin KA et al (2012) Transferred melanoma-specific $\mathrm{CD} 8^{+} \mathrm{T}$ cells persist, mediate tumor regression, and acquire central memory phenotype. Proc Natl Acad Sci USA 109:4592-4597. doi:10.1073/pnas.1113748109

48. Butler MO, Friedlander P, Milstein MI et al (2011) Establishment of antitumor memory in humans using in vitro-educated $\mathrm{CD} 8^{+} \mathrm{T}$ cells. Sci Transl Med 3:80ra34. doi:10.1126/scitranslmed.3002207

49. Alves NL, Arosa FA, van Lier RA (2005) IL-21 sustains CD28 expression on IL-15-activated human naive $\mathrm{CD} 8^{+} \mathrm{T}$ cells. $\mathrm{J}$ Immunol 175:755-762

50. Stemberger C, Huster KM, Koffler M, Anderl F, Schiemann M, Wagner H, Busch DH (2007) A single naive $\mathrm{CD}^{+} \mathrm{T}$ cell precursor can develop into diverse effector and memory subsets. Immunity 27:985-997. doi:10.1016/j.immuni.2007.10.012

51. Uhlin M, Gertow J, Uzunel M et al (2012) Rapid salvage treatment with virus-specific T cells for therapy-resistant disease. Clin Infect Dis 55:1064-1073. doi:10.1093/cid/cis625 